\section{ZUBIRI URBANIZADO: LA FILOSOFÍA DE LA EXPERIENCIA DE I. ELLACURÍA}

\author{
Juan-Antonio Nicolás \\ Universidad de Granada \\ jnicolas@ugr.esl
}

\section{URBANIZED ZUBIRI: I. ELLACURÍA'S PHILOSOPHY OF EXPERIENCE}

Cómo citar este artículo/Citation: Nicolás, J. A. (2016). Zubiri urbanizado: la filosofía de la experiencia de I. Ellacuría. Arbor, 192 (780): a332. doi: http://dx.doi.org/10.3989/ arbor.2016.780n4008

Recibido: 25 julio 2014. Aceptado: 01 septiembre 2015.

RESUMEN: Se interpreta la filosofía de Ellacuría como una filosofía de la experiencia en línea con el giro hacia la facticidad propuesto por Heidegger y asumido por Zubiri. Ellacuría parte de la noción de experiencia de Zubiri como impresión de realidad, pero la transforma a partir del rasgo esencial de la asimetría radical con la que los individuos y los colectivos padecen esa presión de la realidad. Esa diferencia originaria es el motor moral de la crítica filosófica y su superación constituye la meta de la acción. Este camino sólo se puede recorrer desde "el lugar que da verdad", que es la perspectiva de la periferia (marginados, pobres, excluidos, oprimidos, etc.). La propuesta esencial de Ellacuría es poner en el centro de los intereses y de la acción filosófica precisamente a quienes están en los márgenes. Con ello propone una transformación de la metafísica, desde la inversión de la relación centro-periferia. La superación de la asimetría originaria sólo se puede lograr priorizando lo periférico, es decir, poniendo en el centro de atención realmente los intereses y necesidades de quienes la historia y la realidad han relegado a los márgenes.

PALABRAS CLAVE: Experiencia; crítica; maduración; centroperiferia; Zubiri; Ellacuría.
Copyright: (C) 2016 CSIC. Este es un artículo de acceso abierto distribuido bajo los términos de la licencia Creative Commons Attribution (CC BY) España 3.0.
ABSTRACT: The philosophy of Ellacuria is interpreted as a philosophy of experience in line with the turn towards facticity proposed by Heidegger and assumed by Zubiri. Ellacuria starts with Zubiri's notion of experience as an impression of reality, but transforms it from the essential feature of radical asymmetry with which individuals or groups suffer this pressure of reality. This original difference is the moral engine of philosophical criticism, while to overcome it constitutes the goal of the action. This path can only be taken from "the place that renders truth", which is the perspective of the periphery (marginalized, poor, excluded, oppressed, etc.). The essential proposal of Ellacuría is to place at the centre of the interests and philosophical action precisely those who are on the edges. With this, he proposes a transformation of the metaphysical through a reversal of the central-peripheral relationship. The original asymmetry can only be overcome by prioritizing the peripheral -that is, by focusing the centre of attention on the interests and needs of those who have truly been shunted aside by history and reality.

KEYWORDS: Experience; criticism; maturation; centralperipheral; Zubiri; Ellacuría. 


\section{INTRODUCCIÓN: CRÍTICA COMO DESADAPTACIÓN}

Uno de los rasgos característicos de la reflexión filosófica es su carácter normativo, lo que le permite no limitarse a un análisis descriptivo de la realidad, sino aspirar a su crítica y transformación. Frente a esta dimensión del pensar filosófico, hay quienes propugnan que el objetivo del saber (incluido el filosófico) ha de ser la promoción y extensión de conductas adaptativas, tanto en el nivel biológico como en el social y cultural. En particular se viene desarrollando esta orientación en algunas concepciones de un ámbito de reciente creación pero de rápida difusión en la actualidad, como es la neuroética. En cuanto que esta naciente disciplina forma parte de las éticas aplicadas y por tanto se mueve en el ámbito de la razón práctica, no puede limitarse a lo dado (promover conductas de adaptación a lo que hay), sino que ha de incluir una dimensión normativa orientada de algún modo por el deber ser (Cortina, 2012).

En línea con esta tesis, se pretende mostrar aquí cómo en determinados contextos intelectuales y sociales y en un sentido muy preciso, justamente una estrategia no adaptativa puede contribuir al progreso moral, material y cultural de las sociedades; en este sentido se va a plantear un cierto elogio de la inadaptación. En particular se va a mostrar cómo la actitud crítica, reivindicativa y transformadora de I. Ellacuría es un ejemplo de esto. Su actitud no fue de adaptarse a lo que hay, a la realidad dada, al orden establecido, sino que más bien mantuvo una actitud de inconformidad, de no aceptar la situación y llevó esto a su planteamiento filosófico.

Por actitud adaptativa puede entenderse la búsqueda de estrategias de resolución de los problemas que van surgiendo para conseguir con ello mantenerse en el medio de forma viable y no problemática. Pues bien, el pensamiento de Ellacuría puede reconstruirse de modo que precisamente en virtud de la necesidad de resolución de problemas es preciso impugnar lo que hay, empujar su transformación, no adaptarse sino justamente mantener la inadaptación, el rechazo de lo que aparece como inaceptable. Pero para ello es preciso contar con elementos que sólo una razón no restringida puede ofrecer. Se trata de alguna instancia que proceda de, o conecte con algún ámbito extrafáctico, que pueda servir de punto de referencia (bien externo, bien inmanente) desde donde impugnar lo fácticamente dado. Este elemento que no pertenece a lo ya dado puede tener diversos orígenes y muy diferentes formatos. Se trata de las fuentes de la crítica, que de hecho son múltiples en las diferentes corrientes filosóficas hoy vigentes (Nicolás, 2013; Romero, 2010). Tienen en común la capacidad para exigir la transformación de lo que hay, bien porque no satisface las expectativas y aspiraciones creadas, bien porque no se ha desarrollado todo el potencial interno. En cualquier caso, permiten justificar la actividad o actitud crítica, propia de todo saber que ha de avanzar. Así, pueden jugar este papel desde la realidad social o el lenguaje hasta el saber o la propia alteridad de lo real.

Veamos cómo articula Ellacuría su actitud crítica, y por tanto de inadaptación, analizando concretamente el momento más radical de inserción en lo real, esto es, del modo humano de estar en el mundo. Este modo de "estar" no es uno cualquiera, sino que tiene rasgos muy precisos. El ser humano está en el mundo, no "arrojado", ni yuxtapuesto, ni como algo extraño o especial en él, sino que está im-plantado. Esta implantación conlleva todo un arsenal de capacidades y realidades biológicas, psíquicas, históricas, sociales e intelectuales. Para comprender correctamente a Ellacuría en este punto, comenzaremos por revisar el planteamiento de Zubiri al respecto.

\section{LA IMPLANTACIÓN EN LO REAL: EXPERIENCIA Y CRÍTICA}

La reflexión filosófica puede reconstruirse a sí misma, y por tanto a todo el sistema del saber, a partir de unos principios primeros de orden racional, de los cuales de un modo u otro depende el resto de la construcción cognoscitiva. Pero también es posible, y real en ciertos casos, reconstruir todo el cúmulo del conocimiento a partir de determinadas experiencias básicas que constituyen el sustrato que permite toda conceptualización (interpretación, explicación, comprensión). Esta disyuntiva expresa la polémica ya antigua entre la prioridad de lo lógico sobre lo realmaterial o viceversa.

En el caso de Zubiri esta doble vía se aborda y sintetiza desde la noción de aprehensión intelectiva. Toda aprehensión de lo real-material tiene carácter intelectivo y toda conceptuación lógico-racional tiene también carácter físico-material. La aprehensión intelectiva aúna en cada uno de sus niveles estos dos aspectos del saber, de tal modo que ninguno de ellos tiene prioridad sobre el otro. El modo de estar en el mundo no es primariamente interpretativo-comprensivo, ni tampoco lógico-racional ${ }^{1}$. En el mundo estamos implantados aprehensivamente, esto es, físico-intelectivamente. El análisis, reconstrucción e interpretación de este hecho es el punto de partida y el elemento 
determinante de toda la reflexión filosófica. La plataforma intelectual-práctica, compleja y multidimensional constituida en la implantación del ser humano en lo real es lo que se va a entender en este contexto por "experiencia" (cf. Nicolás y Gómez Delgado, 2011). Si se entiende esta implantación, con todos los niveles que abarca, como el escenario de la experiencia humana, puede decirse que tanto la filosofía zubiriana como la de Ellacuría tienen carácter experiencial, y por ello, cada uno a su modo asume el reto heideggeriano de tomar como punto de partida una analítica de la facticidad. Así planteado, el análisis de la facticidad como implantación (aprehensión, asimetría material radical) por parte de Zubiri y Ellacuría detecta elementos que no están tematizados en Heidegger, y que de ningún modo caben en las coordenadas historia y lenguaje, con las que determina Gadamer la facticidad. De este modo, se distancian también de filosofías idealistas trascendentales, algunas de las cuales se han desarrollado en el contexto de la matriz filosófica moderna, generada de Descartes a Kant. Frente a ellas, Zubiri se mantiene en la tesis de que no hay razón pura, pero tampoco hay sensibilidad pura. En la asunción de estas dos tesis se configura la experiencialidad zubiriana (Conill, 1998).

Ahora bien, Zubiri y Ellacuría priorizan aspectos distintos en el análisis del punto de partida original que es la implantación en la realidad, lo cual da lugar a resultados filosóficos relativamente diferenciados. Esto obedece, por un lado, a experiencias vitales profundas distintas entre ambos autores; y por otro lado, la priorización de elementos diferentes en el análisis del nivel originario de implantación en lo real, lo cual conlleva también actitudes distintas ante el objetivo de la reflexión filosófica.

Zubiri expresa su concepción de la experiencia, en una de sus formulaciones más elaboradas, como "impresión de realidad". Lo real presiona originariamente constituyendo así el factum que sirve de punto de partida a la reflexión. Este factum tiene lugar según una forma universal, y por tanto, objeto específico del análisis filosófico. Por su parte Ellacuría parte del factum de que no todo lo real presiona del mismo modo, ni a todos por igual, ni de la misma manera en todos los escenarios. Por ello, su reflexión implica desde el principio un análisis de las diferencias de la presión de lo real sobre los individuos y los colectivos humanos. Hasta el punto de convertir esta diferencia ("asimetría radical" será denominada más adelante) en categoría básica y en motor de la conciencia moral que constituye nuestro modo específico de estar en el mundo.
El análisis de la génesis, estructura y alcance de esta asimetría originaria, y la búsqueda de los modos de su superación atraviesan de modo esencial todo el pensamiento de Ellacuría.

Por otro lado, Zubiri comienza por una descripción de la aprehensión primordial de realidad y del resto de niveles de intelección, entresacando de ahí la forma que presta carácter intelectivo a la aprehensión. Ellacuría, por su parte, pone en primer lugar un interés-exigencia moral ante el análisis de lo aprehendido primordialmente. El dato que considera más relevante es la radical asimetría en cuanto a posibilidad y realidad de autorrealización de los componentes la humanidad, considerados tanto individual como colectivamente, tanto históricamente como en la actualidad. Ante este diagnóstico, Ellacuría confiere prioridad absoluta a la transformación de las condiciones que hacen posible esta realidad. Esto adopta la formulación de un interés emancipador, liberador, crítico-transformador.

La confirmación de esta hipótesis supondría la reafirmación del carácter en última instancia experiencial del pensamiento de ambos filósofos.

Pero, además de experiencial, ambos filósofos imprimen a su pensamiento una dimensión crítica, importante pero distinta en alcance y estructura en cada caso. El pensamiento de Zubiri contiene un potencial crítico cuyo fundamento último está en una interpretación de lo real como fuerza viva, que transmite los caracteres de firmeza y estabilidad (frente a la indigencia del ser) y de imposición en la intelección (frente a la debilidad del pensamiento); esto permite pensar el momento actual y su historia según la metáfora de la maduración, frente a las propuestas que propugnan saltos o vueltas atrás como alternativa a las deficiencias de lo fácticamente dado. Desde el punto de vista epistemológico, este proceso de despliegue o maduración tiene el carácter de "búsqueda" en la que lo real se convierte en "problema" de cara a su interpretación, comprensión y transformación.

¿Cómo situarse en la problematicidad de lo real, en la que esto real es a la vez normativo e inagotable? Por un lado, lo real siempre puede dar más de sí, y por otro lado, la aspiración-necesidad humana (individual y/o colectiva) siempre está incumplida. Esta doble deficiencia constituye el eje de coordenadas en que se sitúa la acción crítica. Y en el que puede situarse el pensamiento de I. Ellacuría, elaborado en gran medida a partir de la filosofía zubiriana, pero con intereses, experiencias e instrumentos propios. Recorre así Ellacuría 
una de las múltiples vías abiertas por el pensamiento de Zubiri. La que tiene como escenario experiencial la situación individual y colectiva de los marginados; la que tiene como perspectiva el devenir histórico, tanto en su dimensión de pasado como, sobre todo, en su orientación al futuro. La que pone en el centro de la reflexión filosófica su interés por la cumplimentación de las necesidades e intereses individuales y colectivos de los seres humanos, y por ello está atravesada por el interés liberador. La que exige el hacerse cargo de la realidad y transformarla, como condición básica de la acción humana en la que se inserta la reflexión filosófica.

Esta es la tesitura en la que, a partir del terreno "salvaje" abierto por Zubiri, Ellacuría urbaniza una zona desplegando su exigencia crítica y liberadora. La fuerza de la que se alimenta esa exigencia crítica es la realidad de la miseria humana y el interés por suprimirla. Esto lleva a Ellacuría a un tipo de crítica mixto, entre la crítica desde la idealidad y la crítica inmanente, con la cual se construye la versión ellacuriana de la dialéctica realidad-razón-realidad en la que se constituye el espacio de la crítica para Zubiri.

\section{IMPLANTACIÓN EN LO REAL: IMPRESIÓN DE REALI- DAD COMO MADURACIÓN}

Zubiri toma pues, como punto de partida de su análisis el hecho de la implantación en lo real, como versión propia del giro hacia la facticidad. Se trata de un giro simultáneo hacia lo fáctico-real y lo fáctico-corporal. Esa implantación es el "enraizamiento" más atrás del cual no es posible retroceder, porque cualquier intento ha de suponerlo. Este es el factum del que parte la noología zubiriana. El análisis zubiriano de este ineludible enraizamiento está orientado a detectar y explicitar la forma según la cual tiene lugar su dinámica propia. Esta es la manera humana de experienciar, de saber, de estar en lo real comprendiéndolo. Según esa formalidad lo real impone su presencia, determinando con ello a la razón y la verdad.

Zubiri concibe la dinámica noológica del intelegir como un proceso dialéctico realidad-razón (+imaginación)-realidad, en el que las nociones de 'sistema de referencia' y 'esbozo' juegan un papel decisivo en la creación del marco crítico cuyo producto es la verdad de lo real inteligido (Nicolás, 2009a). La culminación de este proceso constituye la "experiencia" en toda su riqueza y amplitud, es "el momento terminal del método" (Zubiri, 1983, p. 242). De este modo, la noción de experiencia recubre todo el complejo de implantación en lo real, desde la aprehensión primordial hasta la más elaborada teoría.
Para comprender la dinámica noológica del saber y del estar "plantados" físicamente en la realidad en su unidad, Zubiri utiliza la metáfora biológico-natural de la "maduración" (Nicolás, 2008). Esta categoría expresa para Zubiri "la unidad estructural" de todo el proceso intelectivo, que va de la verdad originaria hasta las verdades derivadas, desde la aprehensión primordial hasta la campalidad y la mundanidad, desde la impresión originaria hasta la razón. Es la unidad de la impresión de realidad en todos sus despliegues, entendida según la lógica de la maduración. Siendo así, esta comprensión de la estructura del aparato intelectivo ha de transmitirse a todas las manifestaciones de éste, sea en la dimensión social del saber, en la dimensión histórica, en la biológica o la científico-formal.

El proceso de constitución del saber no es un proceso de distanciamiento o de degradación desde lo real mismo originario hasta sus múltiples interpretaciones. La metáfora de la maduración implica una lógica diferente, en la cual se avanza hacia la culminación del proceso, hacia el fruto concreto resultado de cada proceso particular con todas sus circunstancias. Esta lógica tiene connotaciones de cumplimiento, de crecimiento, de consumación, en el cual lo precedente alimenta a lo subsecuente y es su condición de posibilidad, no lógico-formal sino real (Zubiri, 1983, pp. 323-324).

Pero por otro lado, maduración es también agotamiento. Culminado el proceso madurativo, el fruto cae del árbol y se pudre. Ha alcanzado su esplendor y autorrealización, pero florecimiento y podredumbre se tocan. Queda, no obstante, un último fogonazo de luz, de vida, de continuidad. Si el fruto cae en terreno fértil, rebrota, genera nueva vida y nuevos frutos. El paso siguiente de la culminación es un nuevo comienzo. Por eso la maduración es a la vez ejecución de posibilidades internas, acabamiento, pero también apertura de nuevas posibilidades y nuevos procesos madurativos. En este contexto Zubiri habla de una cierta "indigencia de la maduración" (Zubiri, 1983, pp. 324), porque implica aniquilación e insuficiencia. Además, la maduración supone atenerse a posibilidades ya dadas de antemano, de modo que el proceso es despliegue y explicitación de lo previamente contenido como posibilidad, y por tanto, todo él depende de lo originariamente dado. Esta instancia se convierte a la vez en vitalizadora y limitadora.

Conviene recordar en este punto que Zubiri no entiende siempre lo posible como anterior a lo real (al estilo, por ejemplo, de Leibniz). Lo real no es una de las múltiples posibilidades lógicas, concretamente aquella que ha accedido a la existencia. En uno de 
sus sentidos, Zubiri conceptualiza la posibilidad como algo subsiguiente a lo real, que se genera en y depende de lo real. Las posibilidades aparecen en el devenir de la realidad o no, según se vaya construyendo ésta. Un determinado momento, o una determinada situación social real puede tener o no, por ejemplo, la posibilidad de acceder al saber por vía Internet. La apropiación de esa posibilidad abre nuevas opciones reales, y su abandono cierra ese conjunto de posibilidades. El horizonte de posibilidades reales es el que marca tanto las expectativas como las deficiencias. No poder acceder a Internet a estas alturas de comienzos del siglo XXI en un país europeo es una grave limitación y déficit, porque esa es una posibilidad real, pero no lo sería en ese mismo lugar en el s. XVII. Las posibilidades reales están ligadas a circunstancias concretas de muy diversos orígenes, y que pueden ser apropiadas o no individual y colectivamente ${ }^{2}$. De este modo el horizonte de posibilidades reales constituye uno de los componentes de la crítica. Ellacuría aprovechará este planteamiento (Nicolás, 2009b).

\section{IMPLANTACIÓN EN LO REAL: DE LA MADURACIÓN A LA HISTORICIDAD}

Ellacuría, como es bien conocido, prioriza la historia, no en cuanto modo específico de saber, sino como "carácter de la realidad", como dimensión totalizadora y, por ende, como objeto específico de la reflexión filosófica. La historia tiene un componente natural y material, pero no ha de interpretarse "naturalistamente" (Ellacuría, 1991a, pp. 136-137). La historia no es sin más naturaleza, aunque no podría tener lugar sin ella, y en esto sigue a Zubiri. El modo de estar en lo real no está determinado por mecanismos biológicos, genéticos o físicos, aunque estos sean una de sus condiciones de posibilidad. Y la historicidad pertenece al conjunto de los elementos constitutivos del modo de estar implantado en lo real, es "posibilitación de modos de estar en la realidad" (Zubiri, 2006, p. 139). Historicidad es un rasgo del modo humano de estar en el mundo.

Justamente por ello, para concebir la historia Ellacuría se aparta de la dinámica de la maduración como rectora del proceso intelectivo. La historicidad requiere otra dinámica diferente de la maduración. Siguiendo también a Zubiri, rechaza lo que de "natural" (Ellacuría, 1991a, p. 421) hay en la metáfora de la maduración, porque el foco de su atención está puesto en la consideración de la historia como algo que está por hacer, la historia como tarea. Para comprender la realidad en cuanto histórica no se puede partir del modelo biológico de la germinación, o realización de posibilidades ya contenidas desde el principio. El modo histórico de estar en lo real incluye categorías como espontaneidad, ruptura, invención, decisión, opción, responsabilidad, creación, etc. Toda esta categorización difícilmente puede integrarse en un modelo de base biológica. La forma que constituye lo específico de la historicidad de la implantación humana en la realidad se construye con la constelación de categorías mencionada. Hasta aquí Ellacuría sigue básicamente a Zubiri cuando habla del ser humano como "creador de posibilidades".

Pero no se trata de reproducir la concepción de la historia por parte de Ellacuría, sino de intentar explicar un aspecto, quizás mínimo pero relevante, del camino propio seguido por Ellacuría respecto a Zubiri. Siguiendo con la lógica de esta reflexión, la cuestión es cómo es el análisis ellacuriano del modo humano de estar im-plantados en la realidad y cuál es la experiencia determinante que le lleva a su posición filosófica final, tanto en lo relativo a su concepción de la historia como a su posición política y social.

\section{IMPLANTACIÓN COMO TRANSFORMACIÓN: DE LA FORMALIDAD A LA ASIMETRÍA MATERIAL REAL}

Ellacuría propugna un análisis historizado de nuestro estar en el mundo, que se aleja del análisis orientado a la búsqueda de un mínimo formal común. Este análisis historizado "consiste en ver cómo se está realizando, en una circunstancia dada, lo que se afirma abstractamente como un deber ser" (Ellacuría, 2001, p. 217; cf. Tamayo, 2007).

Ante la formalidad de la intelección descrita por Zubiri en su teoría de la inteligencia sentiente, Ellacuría añade un ingrediente que sirve para adoptar el punto de vista epistemológica o intelectivamente adecuado. Para alcanzar la verdad Ellacuría eleva las circunstancias concretas al mismo nivel de las formas universales. No se trata solamente de dilucidar que la noción de 'opción' es propia del análisis que adopta la perspectiva de la 'historicidad'; sino que hay que determinar además cuál es la opción adecuada para alcanzar una intelección verdadera. Y sin este segundo paso, se puede permanecer en una mera abstracción formal universalista, y no se está en la orientación adecuada para alcanzar la verdad. Verdad y praxis concreta quedan así ligadas.

Sólo así puede haber intelección real del mundo real. Lo particular concreto, llevado a un segundo plano ontológico en la tradición aristotélica, ocupan ahora un lugar constitutivo, quedando con ello mucho más 
cerca de Hegel. En esta perspectiva el análisis y reconstrucción de la acción intelectiva no tiene por objetivo identificar estructuras formales, axiológicamente neutras, esto es, libres de valores. El análisis ellacuriano de la implantación en la realidad huye de todo neutralismo, porque parte de la tesis de que en la realidad estamos ya decantados, en una determinada posición, oprimidos u oprimiendo, estamos ya en un mundo de intereses contrapuestos. Por ello el análisis del punto de partida ha de contar ya con ello y hacerlo jugar en el mismo. La pauperización "es la verdad histórica del presunto bien común" (Ellacuría, 2001, p. 220). Ante este malestar radical de nuestra cultura como diagnóstico de partida, el pensamiento de Ellacuría no pivota sobre la angustia (Heidegger), ni sobre una descripción del nivel básico de inserción en lo real (Husserl), sino que aprovechando el planteamiento de Zubiri, quiere rebasar a ambos desde un decidido e ineludible objetivo emancipador. Si Zubiri parte del análisis de un hecho (el estar intelectivo en el mundo) como aprehensión, Ellacuría reinterpreta e integra en el análisis del hecho originario un interés que valora como ineludible y en este sentido, como necesario. Se trata del interés por la liberación humana. Lo aprehendido en la aprehensión no sólo tiene una formalidad, sino que uno de sus contenidos esenciales es la asimetría radical en la autorrealización humana. Y esto plantea la exigencia de su reforma, si nuestro modo de estar en el mundo quiere estar a la altura moral que la humanidad ha conquistado como propia, porque en ella se reconoce. En este sentido preciso, puede decirse que con Ellacuría la intelección se reinterpreta en unos términos tales que contiene en su fondo último una exigencia de transformación (como modo de entender y recorrer aquélla). El análisis de nuestro estar implantado en lo real está orientado (dirigido, condicionado) para Ellacuría por ese ingrediente esencial de la aprehensión que es el interés-exigencia transformador-liberador.

Dada esta situación desde la que se hace el análisis filosófico, no caben neutralidades, por lo que callar al respecto contribuye de hecho a consolidar lo que hay. La objetivación en un sistema jurídico que legitima la situación dada mientras proclama un discurso público de bienes y derechos universales, es el signo más claro de la esencialidad de lo circunstancial. Si no se ponen los mecanismos necesarios para crear las condiciones necesarias que permitan ejecutar efectivamente lo que se proclama como derecho universal, entonces se está en un ejercicio de falsedad, de ideologización en el peor de los sentidos, en última instancia, en un caso de cinismo, por más que tenga carácter público, universal y jurídicamente legítimo ${ }^{3}$.
En coherencia con esto, Ellacuría pone a la base de su reflexión, como punto de partida una opción, la "opción por los pobres" (Ellacuría, 2000). No se trata de un comienzo irracional para exigir posteriormente la racionalidad propia de un determinado modelo. Esta opción es ya un ejercicio de intelección, dicho en terminología zubiriana; el punto de partida no es algo ya dado, sino que a él se llega, ha de alcanzarse. El modo ellacuriano de comprender el punto de partida de la intelección es la "toma de partido" (Nicolás, $2009 b)$, apoyada en lo que él llama "discernimiento". Esta es la consecuencia del rasgo esencial constitutivo del punto de partida que es la asimetría en cuanto a posibilidades de autorrealización. Ante tal asimetría se hace necesaria una opción en el análisis de la situación. Puesto que "en lo real estamos ya" cuando comienza el proceso intelectivo y el proceso analíticocomunicativo (y crítico) que es la filosofía, no caben equidistancias, ni neutralidades ni asepsias. Para que no se trate de un elemento dogmático en origen mismo de la reflexión filosófica, ha de ser explicitado, analizado y decidido. En una situación asimétrica, ¿de qué parte está el filósofo? He aquí desnuda y abiertamente planteada la exigencia moral que hay a la base de toda vida humana que quiera ser honesta con lo real. He aquí la exigencia explícita de Ellacuría a toda acción filosófica de conexión entre reflexión y acción, entre especulación y compromiso real.

Este es el motivo último por el que Ellacuría mediatiza todo su análisis por un interés supremo, convertido en categoría: la liberación. El análisis ha de ser interesado, no puede pretender neutralidad, y el interés último es la liberación. El interés analítico-intelectivo adopta la forma de interés liberador, que tiene como exigencia fundamental la transformación de lo real. Siguiendo el uso zubiriano de la noción de libertad, en su vertiente negativa (libertad de) y positiva (libertad para $)^{4}$, Ellacuría liga la noción de libertad, no a un mundo de posibilidades por realizar, sino a la acción efectiva, al ámbito real de la praxis concreta. De este modo, la dimensión transformadora-liberadora adquiere la prioridad gnoseológica y ontológico-social en el pensamiento de Ellacuría, con lo que queda desbordado ya cualquier concepción naturalista de la historia.

Para estructurar internamente esta tesis, Ellacuría recurre prioritariamente al par de categorías centroperiferia (Ellacuría, 2001, p. 219). Esta categorización ofrece mucho juego a Ellacuría, en muy variadas formulaciones: pobres-ricos, opresores-oprimidos, poderosos-dependientes, dominadores-dominados, privilegiados-desposeídos, integrados-excluidos, etc. 
Siempre hay en estos pares de nociones un centro con poder y una periferia disminuida, rebajada o impotente. Pues bien, un rasgo típico del pensamiento de Ellacuría es convertir la periferia en centro, lo marginal como objetivo central, poner como elemento determinante aquello que en otras concepciones, o simplemente en la realidad, es considerado periférico. Hasta el punto de convertir lo marginal en criterio y baremo para medir y valorar la realidad social. Esta es una de las transformaciones epistemológicas con más repercusiones del pensamiento ellacuriano. Con esta propuesta Ellacuría está buscando otro modo de pensar-actuar diferente desde su raíz y su motivación, por lo que puede interpretarse como una propuesta de transformación de la metafísica, en la que teoría y praxis interactúan directamente, y en la que los marginados tienen la primera y decisiva palabra. Podría formularse como una "transformación marginalista de la metafísica", o una "metafísica de la marginalidad".

Desde el punto de vista epistemológico-social esta transformación incorpora la importancia fundamental que tiene el lugar experiencial desde el que se plantea y desarrolla la reflexión filosófica y la consecuente acción racional. Precisamente la perspectiva de la periferia y de lo marginal (por ejemplo, de los pobres) pone de manifiesto lo que en una perspectiva desde el poder queda oculto. Pero adoptar esta perspectiva requiere no sólo pensar determinadas cosas, sino también pasar por determinadas experiencias. Por ello Ellacuría llama a esta perspectiva, "el lugar que da verdad" (Ellacuría, 1991b, p. 115), porque permite el acceso a un ámbito de la condición humana que desde otros puntos de vista resultan difícilmente accesibles. Esta concepción de la verdad está ya transformada según la exigencia de historización requerida para todo proceso intelectivo. Por ello no tiene el formato de una proposición o una tesis ya verificada, sino el de una tarea permanente de creación, valoración y acción. Esta disponibilidad para la verdad es un modo de estar en el mundo que puede adoptarse en toda situación concreta, del mismo modo que puede resultar también inalcanzable en cualquier circunstancia, si la situación hermenéutico-experiencial no es la adecuada. He aquí la exigencia racional de un compromiso con la acción como condición para la orientación hacia la verdad. "Separada de estas praxis es difícil que la filosofía se constituya como tal, más difícil aún es que se constituya como liberadora y más difícil aún es que contribuya realmente a la liberación" (Ellacuría, 1991b, p. 120). En la medida en que este tipo de praxis es posible en cualquier situación concreta y además está orientada por un interés que afecta a todo ser humano (en cuanto individuo o en cuanto miembro de una comunidad), puede decirse que este planteamiento sintetiza universalidad racional y particularidad histórica. He aquí la versión ellacuriana de la 'verdad real' de Zubiri, conectada con la acción y dimensionada como historia, incluyendo sus despliegues lógico-racionales y experienciales.

Esta transformación va unida, por último, a una determinada relación entre la parte y el todo. El objetivo de la acción ha de ser "la participación inmediata del mayor número de integrantes de la sociedad" (Ellacuría, 2001, p. 225) en lo que son los bienes comunes, lo que la sociedad produce. Pero este objetivo pasa por atender antes a los que menos tienen, a aquellos que participan en menor medida en los bienes de la sociedad; los intereses de los que han quedado fuera han de tener prioridad. Este es el modo de evitar que los intereses de los que dominan la sociedad se identifiquen con los intereses del conjunto de la sociedad y además reciban la legitimidad y la cobertura legal del sistema jurídico. No ha de olvidarse que el tejido legal se elabora desde el poder político-legislativo, en frecuente connivencia con quienes más capacidad de influencia tienen.

\section{LA EXPERIENCIA DETERMINANTE: VERDAD Y JUSTICIA}

La situación hermenéutica en que tiene lugar la intelección está delimitada por un lado por un interés "universal" como es la liberación individual y colectiva de los seres humanos, y las circunstancias concretas que perfilan esencialmente cada caso y cada situación. Es así como Ellacuría incorpora la experiencia concreta al núcleo mismo del punto de partida de la reflexión. Y la valoración de los ingredientes que configuran cada situación particular constituyen el criterio o baremo para evaluar el devenir de la realidad social, esto es, la consecución del objetivo de la acción racional que es la liberación de la totalidad de la humanidad, mediante la resolución de las necesidades básicas y la cumplimentación de sus intereses.

Finalmente, ¿cuál es la experiencia que lleva a Ellacuría a propugnar esta transformación gnoseológica y socio-política, y que le sirve de fuente última de su inadaptación, esto es, de su actitud crítica frente a lo dado? La respuesta a esta pregunta no puede ser contestada en una sola frase, porque esa experiencia sin duda fue el cúmulo de multitud de vivencias, reflexiones, deseos, logros, fracasos, conocimientos, etc.

Ahora bien, como aportación para avanzar en la exploración de esta base experiencial, puede si- 
tuarse, sin duda, lo que Ellacuría llamó "una sociedad injustamente estructurada" (Ellacuría, 2001, p. 224). Esto fue una herida clavada de modo definitivo en el corazón y la mente de Ignacio Ellacuría, que vivió esta experiencia en primera persona en Centroamérica, pero que es una experiencia común en cualquier rincón donde esté presente la humanidad. En cuanto que esta experiencia fue decisiva para la construcción de su pensamiento, estamos ante uno de los sentidos en que la filosofía de Ellacuría puede llamarse experiencial: parte de la experiencia (propia y colectiva) y quiere forzar a su vez un determinado camino de la experiencia social futura, en un alarde de inadaptación. Así la historia y la verdad han de ser construidas dentro de las coordenadas que son la realidad fácticamente dada, por un lado, y aquello que esta misma realidad exige como irrenunciable, respecto al baremo que es lo humanamente digno, tal y como es entendido en cada momento y en cada sociedad. El proceso de posibilidades a crear es inabarcable en ningún momento particular de la historia.

Esta experiencia se plasma y se expresa de modos muy distintos. Por tomar algún referente conocido, puede formularse en contraste con el lema de la llustración: frente a libertad, igualdad, fraternidad, Ellacuría vivió y sufrió el sometimiento, la desigualdad y la indiferencia. Por ello, la implantación en lo real sólo podía tener la forma inadaptada de transformación liberadora, y al servicio de esta causa puso su vida.

\section{AGRADECIMIENTOS}

Este artículo se ha realizado con el apoyo del proyecto de investigación HUM2010 FFI2010-15914 financiado por el Ministerio de Economía y Competitividad y del Grupo de Investigación del PAIDI (Junta de Andalucía) número HUM-432.

\section{NOTAS}

1. Zubiri aborda el papel metodológico de la 'comprensión' en la noología fundamentalmente en Inteligencia y razón (1983), cap. 8, pp. 327-352. Sobre este tema puede verse Nicolás, J.A.; Barroso, O (2005); y Conill, J. (2008). Y respecto a la relación entre comprensión e historia puede verse Reyes Linares, P. A. (2004),

2. Luis José González ha destacado el aspecto de la constitución social de las posibilidades reales aplicado al ámbito de la moralidad. Cf. González Álvarez, L.J. (2007).

3. En este punto puede detectarse una interesante convergencia del pensamien-

\section{BIBLIOGRAFÍA}

Conill, J. (1998). Concepciones de la experiencia. Diálogo Filosófico, 41, pp. 148-169.

Conill, J. (2008). Zubiri y Heidegger desde Ortega y Gasset. Entre fenomenologías y más allá. En: Nicolás, J. A. y Espinoza, R. (eds.) Zubiri ante Heidegger, Barcelona: Herder, pp. 81-106.

Cortina, A. (2012), Neuroética: presente y futuro. En: Cortina, A. (ed.) Guía Comares de Neurofilosofia práctica. Granada: Comares, pp. 9-37.

Ellacuría, I. (1991a). Filosofía de la realidad histórica. Madrid: Trotta. to de Ellacuría con el de la Pragmática trascendental del lenguaje en la versión elaborada por Kart Otto Apel. Para éste el plano de la fundamentación, que busca condiciones trascendentales del hecho de la acción comunicativa ha de complementarse con el plano B de la aplicación; y por ello resulta esencial atender a las condiciones de aplicación y de funcionamiento real de cada acto de comunicación y constituye la tarea primera la consecución (nunca lograble) de las condiciones ideales de comunicación. Por su parte, Ellacuría huyendo del universalismo abstracto, modifica la relación entre universalidad

Ellacuría, I. (1991b). La función liberadora de la filosofía. En: Ellacuría, I. Escritos políticos I. San Salvador: UCA editores, pp. 93-121.

Ellacuría, I. (2000), Opción preferencial por los pobres. En: Escritos Teológicos II. San Salvador: UCA editores, pp.133-192.

Ellacuría, I. (2001). Historización del bien común y de los derechos humanos en una sociedad dividida. En: Ellacuría, I. Escritos filosóficos III. San Salvador: UCA editores, pp. 207-225.

González Álvarez, L. J. (2007). Sentido moral, sistema de valores y sistema y particularidad o circunstancias concretas. Estas últimas cobran un valor que no tienen para Apel en el nivel de la reflexión filosófica. No obstante, es muy importante destacar que Ellacuría no renuncia en ningún momento a la dimensión de universalidad que ha de tener el saber filosófico.

4. “La interna articulación de la libertad en sentido negativo (libertad de) y la libertad en sentido positivo (libertad para) confiere una figura concreta y finita a la libertad de cada hombre en cada momento de su existencia", Zubiri, X., 1986, p. 145. 
Nicolás, J. A. (2009b). Liberation philosophy as critique: Ellacuría. The Xavier Zubiri Review, 11, pp. 107-118.

Nicolás, J. A. (2013). La crítica filosófica y sus fuentes. Diálogo Filosófico, 85, pp. 4-35.

Nicolás, J. A. y Barroso, O. (2005), Comprensión y realidad. Zubiri ante el reto hermenéutico. Endoxa, 20, pp. 773794. http://dx.doi.org/10.5944/endoxa.20.2005.5152

Nicolás, J. A. y Espinoza, R. (eds.) (2008). Zubiri ante Heidegger. Barcelona: Herder.
Nicolás, J. A. y Gómez Delgado, J. M. (2011). Los límites de mi experiencia son mis límites. La naturaleza humana de Hume a Zubiri. Agora, 30, pp. 87-103.

Nicolás, J. A. y Samour (eds.) (2007). Historia, ética y ciencia. El impulso crítico de la filosofía de Zubiri, Granada: Comares.

Reyes Linares, P. A. (2004). La comprensión como fuerza personal constitutiva en el proceso histórico. The Xavier Zubiri Review, 6, pp. 105-114.

Romero, J. M. (2010). Crítica e historicidad. Barcelona: Herder.
Tamayo, J. J. (2007). El método de historización de los conceptos teológicos en Ellacuría. En: Nicolás, J. A. y Samour, H. (eds.) Historia, ética y ciencia. El impulso crítico de la filosofía de Zubiri. Granada: Comares, pp 175-211.

Zubiri, X. (1983). Inteligencia y razón. Madrid: Alianza.

Zubiri, X. (1986). Sobre el hombre. Madrid: Alianza.

Zubiri, X. (2006). La dimensión histórica del ser humano. En Zubiri, X. Tres dimensiones del ser humano: individual, social, histórica, Madrid: Alianza, pp.105-168. 